\title{
ANALISA JARINGAN WIRELESS LAN DENGAN MENGGUNAKAN APLIKASI EKAHAU SITE SURVEY (STUDI KASUS STMIK KHARISMA KARAWANG)
}

\author{
Wahyudi \\ STMIK Kharisma Karawang, Sistem Informasi \\ wahyudi008@gmail.com \\ Jl. Pangkal Perjuangan Km.1, Karawang Barat, Jawa Barat
}

\begin{abstract}
ABSTRAK
Dengan berkembangnya sistem pengajaran dikampus STMIK Kharisma saat ini diperlukan suatu koneksi jaringan yang memadai, salah satunya adalah koneksi jaringan yang berbasis Wireless LAN, di mana dibutuhkan koneksi yang handal untuk mendukung terciptanya sistem belajar dan mengajar yang baik. Saat ini hamper seluruh lantai sudah terpasang access point.Tujuan dari penulisan ini adalah pengetahuan jangkauan Access point yang sudah terpasang saat ini, apakah sudah dapat me-cover seluruh area kampus Kharisma, dengan cara melakukan pemantauan jangkauan setiap access point yang terpasang disetiap lantainya. Penulisan ini juga akan menjelaskan kelebihan dan kekurangan WLAN yang terdapat di STMIK Kharisma berupa analisa yang diperoleh dari hasil penelitian yang dilakukan. Pemetaan access point menggunakan aplikasi ekahau site survey dimana aplikasi ini dapat memetakan seberapa jauh jangkauan yang dihasilkan oleh setiap access point.
\end{abstract}

Kata kunci : Wireless LAN, Access point, Jaringan Kampus, ekahau site survey.

\section{PENDAHULUAN}

Seiring dengan perkembangan teknologi jaringan khusus jaringan nirkabel dimana pengguna dimudahkan untuk dapat saling berkomunikasi satu dengan yang lain tanpa ada batas ruang dan waktu. Dengan jaringan nirkabel efisiensi belajar mengajar lebih dapat ditingkatkan. Salah satu keuntungan dari jaringan nirkabel adalah pengguna dapat bergerak kemana saja dengan perangkat mereka dan mengirim data pada saat yang bersamaan. Keuntungan lain adalah kemudahan dalam pemasangan, fleksibilitas dan menghemat biaya. Disamping kelebihan diatas jaringan nirkabel juga memiliki kelemahan yaitu semakin lemah nya frekuensi radio yang dipancarkan jika terhalang oleh tembok atau dinding yang akan mengakibatkan lemahnya sinyal yang diterima oleh pengguna.

Tujuan dari penelitian ini adalah mengetahui sejauh mana jangkauan frekuensi radio yang dipancarkan oleh setiap access point yang terdapat pada jaringan nirkabel di kampus STMIK Kharisma, sehingga dapat dipetakan area mana yang tidak terjangkau atau memiliki penerimaan signal yang lemah dari setiap access point yang terpasang saat ini dan perbaikan-perbaikan apa yang harus dilakukan.

\section{LANDASAN TEORI}

Saat ini ada banyak jenis jaringan komputer di dunia, seperti ditunjukan pada gambar 1, seperti Wide Area Network (WAN), Metropolitan Area Network (MAN), dan Local Area Network (LAN), Personal Area Network (PAN). Sedangkan jaringan nirkabel atau wireless LAN termasuk dalam salah satu jenis LAN.

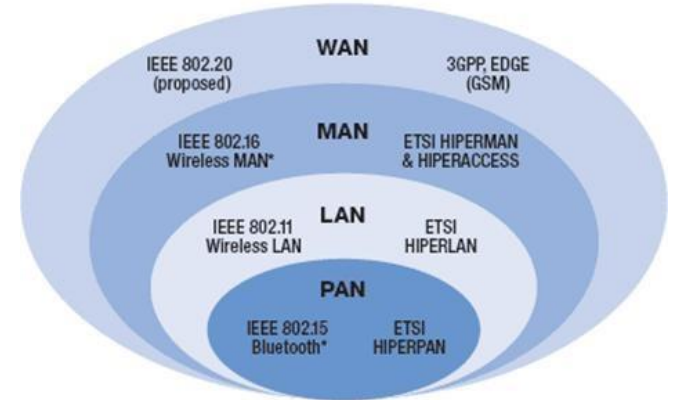

Gambar 1 : Standard Wireless Global (Naren Tada : 2012)

Jaringan nirkabel menggunakan gelombang infrared atau radio untuk menyediakan jaringan bagi perangkat nirkabel dan memungkinkan pengguna untuk mengirim data satu sama lain di area yang terjangkau oleh access point tanpa menggunakan kabel. Wireless LAN memiliki protocol jaringan nirkabel yang berbeda, seperti IEEE802.11, Bluetooth, HomeRF dan HiperLAN. Banyak perangkat nirkabel mendukung WLAN, termasuk ponsel, console game, kamera, tablet dan juga system GPS. WLAN dapat berisi dua perangkat atau hingga seratus atau lebih.( Bradley 2019.) 


\subsection{Keuntungan dan Kerugian Jaringan Nirkabel}

Jaringan nirkabel memiliki beberapa keunggulan yaitu jaringan nirkabel lebih fleksibel dan mudah berpindah dari satu tempat ketempat lain dibandingkan dengan menggunakan kabel. Pengguna dapat memiliki akses ke atau menerima informasi secara real time. Kedua nirkabel juga memiliki skalabilitas yang baik, pengguna dapat menambahkan lebih banyak Access point (AP) untuk memperluas jaringan secara efektif sehingga dapat memenuhi kebutuhan. Ketiga, WLAN tidak lagi membutuhkan kabel yang dapat mengurangi beban kerja pemasangan jaringan kabel.

Kerugian jaringan nirkabel adalah pertama, WLAN didasarkan pada frekuensi radio untuk transmisi data, sehingga tidak boleh ada penghalang seperti dinding atau bangunan yang dapat menghalangi transmisi frekuensi radio yang dapat menyebabkan berkurangnya kekuatan sinyal dan akan mempengaruhi kinerja dari WLAN. Kedua kemungkinan terjadinya interferensi yang diakibatkan ada beberapa perangkat yang memiliki frekuensi yang sama dengan seri 802.11 dan dapat menyebabkan terganggunya sinyal radio. Ketiga dari sisi keamanan jaringan berbasis nirkabel lebih rentan dibandingkan dengan yang berbasis kabel. Keempat jangkuan dari WLAN terbatas, WLAN memiliki jangkauan terbatas jadi diperlukan biaya yang lebih besar untuk meningkatkan jangkauan dari sebuah hot spot. (Bradley : 2019).

\subsection{Media transmisi Wireless LAN}

Terdapat tiga media transmisi pada Wireless LAN. Pertama adalah microwave dan memiliki rentang frekuensi antara $1 \mathrm{GHz}$ sampai $40 \mathrm{GHz}$. Microwave bukan arti sesungguhnya dari teknologi LAN. Ini digunakan untuk menghubungkan antara gedung pada local area network. Sangat cocok untuk transmisi point to point dan komunikasi satellite. Kedua adalah media radio dan memiliki rentang frekuensi $3 \mathrm{KHz}$ sampai $300 \mathrm{GHz}$. Media transmisi ini banyak digunakan karena gelombang radionya memiliki jangkauan yang luas. Ini cocok untuk semua aplikasi. Perbedaan keduanya adalah tidak membutuhkan antenna. Dan radio memiliki bentuk omnidirectional dan microwave memiliki bentuk directional. Dan yang ketiga adalah infrared. Infrared digunakan untuk mengirim dan menerima modulasi cahaya infrared yang tidak koheren. Perbedaan antara transmisi infrared dan microwave adalah cahaya infrared tidak dapat menembus dinding. Dan tidak perlu pengalokasikan frekuensi karena tidak membutuhkan license (Vittorio : 2008).

\subsection{Standard dari Wireless Local Area Network}

Pengguna memiliki banyak pilihan ketika akan mencari perangkat jaringan. Banyak produk yang compatible dengan 802.11 atau juga dikenal dengan teknologi Wi-Fi. Ada berbagai macam teknologi wireless seperti Bluetooths, HomeRF dan HiperLAN. Mereka dirancang untuk aplikasi jaringan spesifik.

\subsection{Series}

Komite standard IEEE 802 mendefinisikan menjadi 2 layer, yaitu Logical Link Control (LLC) dan Media Access Control yang terdapat pada layer Data-Link pada Model OSI Layer seperti yang ditunjukan pada gambar 2 berikut ini

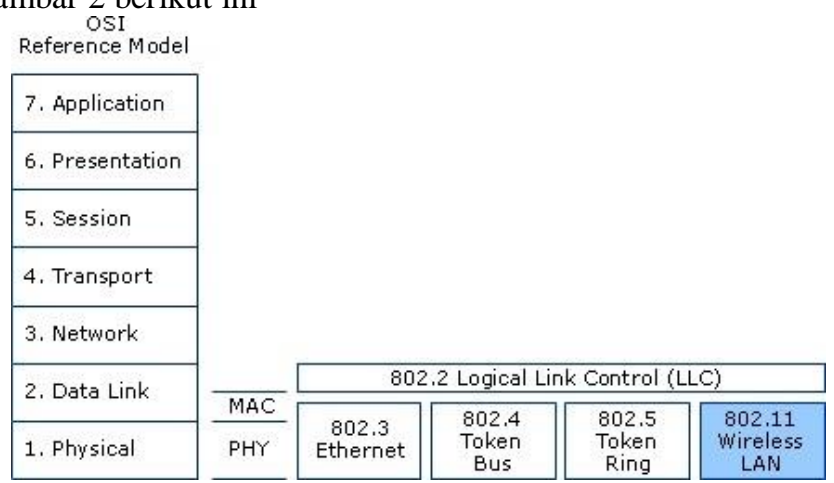

Gambar 2. OSI Model dan 802 (802.11 Wireless Technical Reference)

Semua komponen dalam arsitektur 802.11 terdapat dalam media access control (MAC) sublayer dari data link layer atau physical layer.

Standar pertama dari seri 802.11 muncul tahun 1997 yang dibuat oleh IEEE. Saat itu 802.11 hanya mendukung bandwidth 2 MBps menggunakan skema transmisi FHSS dan S-Band Industrial, Scientific dan Medical (ISM), dimana frekuensi yang digunakan memiliki rentang $2.4 \mathrm{GHz}$ sampai 2.5 GHz. dan untuk saat ini kondisi tersebut sudah tidak memandai.

Versi 802.11b diperkenalkan tahun 1999 yang memiliki kecepatan lebih tinggi dibandingkan versi sebelumnya, dimana pada versi ini mendukung kecepatan 5,5 MBps dan 11 MBps dengan menggunakan S-Band. 802.11b menggunakan frekuensi 2,4GHz yang memiliki jangkauan sinyal lebih baik dari 802.11a dan memiliki jangkuan jarak yang lebih jauh yaitu 100 meter untuk indoor dan 300 meter untuk outdoor. 802.11b menggunakan frekuensi yang sama 
dengan yang digunakan oven microwave, telepon cordless, wireless kamera video dan perangkat Bluetooth sehingga memungkinkan terjadinya interferensi jika digunakan secara bersama.

Versi 802.11a dibuat bersamaan dengan 802.11b yang memiliki kecepatan 54 MBps dan menggunakan C-Band ISM, beroperasi difrekuensi dengan rentang 5,725 GHz sampai 5,875 GHz, menggunakan Orthogonal Frequency Division Multiplexing (OFDM). OFDM adalah teknik pengkodean yang membagi sinyal radio menjadi beberapa sub sinyal sebelum mencapai penerima. Menggunakan OFDM akan mengurangi gangguan antar sinyal. 802.11a memiliki kecepatan dan frekuensi yang lebih tinggi daripada 802.11 b, tetapi 802.11 a memiliki sinyal jarak pendek dan mudah terhambat. (Instrumen Nasional 2015.).

Versi 802.11g muncul pada tahun 2002. Mendukung bandwidth 54 Mbps dan frekuensi 2,4 GHz. Menggunakan S-Band ISM dan OFDM. Versi ini dibuat untuk interoperabilitas antara 802.11a dan 802.11b. 802.11g menggunakan teknologi OFDM. Menurut Bradley, 802.11g dirancang untuk kompatibilitas dengan versi-versi sebelumnya, perangkat tersebut dapat bergabung dengan jaringan, bahkan AP yang berjalan pada versi 802.11 yang berbeda.

Versi $802.11 \mathrm{n}$ adalah pengembangan dari 802.11g. Kecepatannya meningkat menjadi 600Mbps. Dan mendukung frekuensi $2.4 \mathrm{GHz}$ dan $5 \mathrm{GHz}$. 802.11n dapat meningkatkan kualitas transmisi nirkabel. Ini menggabungkan teknologi MIMO dan OFDM. MIMO berarti multiple in multiple out dan umumnya digunakan di router untuk penggunaan antena multi-radio yang terkoordinasi dalam jaringan nirkabel. Teknologi MIMO dapat meningkatkan bandwidth dan jangkauan jaringan. (Bradley 2019.)

Versi 802.11ac adalah yang terpopuler di pasar saat ini. Versi ini muncul pada tahun 2012. Ini adalah versi yang lebih cepat dan terukur dari 802.11n. 802.11ac mendukung kecepatan data $1 \mathrm{Gbps}$ dan frekuensi 5GHz. Perbandingan antara berbagai teknologi WLAN 802.11 ada pada Tabel 1 .

\begin{tabular}{|l|c|c|c|c|c|}
\hline IEEE Standard & $802.11 \mathrm{~b}$ & $802.11 \mathrm{a}$ & $802.11 \mathrm{~g}$ & $802.11 \mathrm{n}$ & $802.11 \mathrm{ac}$ \\
\hline Release Years & 1999 & 1999 & 2003 & 2009 & 2012 \\
\hline Frequency & $2.4 \mathrm{GHz}$ & $5 \mathrm{GHz}$ & $2.4 \mathrm{GHz}$ & 2.4 or $5 \mathrm{GHz}$ & $5 \mathrm{GHz}$ \\
\hline Data Rate & $11 \mathrm{MBps}$ & $54 \mathrm{MBps}$ & $54 \mathrm{MBps}$ & $600 \mathrm{MBps}$ & $1 \mathrm{GBps}$ \\
\hline Modulation & DSSS & OFDM & DSSS, OFDM & OFDM & OFDM \\
\hline
\end{tabular}

Tabel $1: 802.11$ Wireless Standard

Terlihat jelas pada table tersebut bahwa kecepatan data menjadi lebih cepat seiring berjalannya waktu. 802.11 Series menggunakan frekuensi dan modulasi berbeda untuk memenuhi berbagai kebutuhan.

\subsubsection{Bluetooth}

Bluetooth adalah protokol komunikasi nirkabel yang dibuat pada tahun 1994 oleh perusahaan Ericsson dan digunakan untuk menghubungkan perangkat melalui udara. Bluetooth lebih lambat dari WI-FI, tetapi mudah digunakan dan biasanya dipakai untuk transfer data antar perangkat. Ini dapat membantu perangkat mengirim data antara satu sama lain dalam jarak 10 meter. Bluetooth bekerja pada frekuensi $2.4 \mathrm{GHz}$ dengan kecepatan data sekitar $1 \mathrm{Mb} / \mathrm{s}$. Bluetooth paling umum digunakan ponsel untuk transfer foto atau file. Menurut Samraiz (2014), ada sejumlah versi Bluetooth yang sedang dikembangkan untuk memenuhi persyaratan khusus saat itu. Semua versi Bluetooth yang diperbarui kompatibel dengan versi-versi sebelumnya. Pengguna juga dapat mentransfer data melalui WLAN. Namun ada perbedaan antara WLAN dan Bluetooth. Bluetooth bekerja dalam jangkauan jarak yang lebih rendah daripada di WLAN. WLAN juga lebih cepat dari Bluetooth. Namun terkadang Bluetooth adalah pilihan yang lebih baik ketika pengguna perlu mentransfer data antar ponsel. Tabel 2 menunjukkan tentang perbandingan antara 802.11b dan Bluetooth. 


\begin{tabular}{|c|c|c|}
\hline & Wireless LAN & Bluetooth \\
\hline Definisi & $\begin{array}{l}\text { WLAN kepanjangan dari Wireless } \\
\text { Local Area Network. Menghubung } \\
\text { kan dua atau lebih perangkat meng } \\
\text { gunakan koneksi wireless data } \\
\text { dengan jarak pendek }\end{array}$ & $\begin{array}{l}\text { Bluetooth adalah standar } \\
\text { teknologi jarak pendek yang } \\
\text { memungkinkan perangkat } \\
\text { berkomunikasi secara nirkabel }\end{array}$ \\
\hline Rentang Jarak & diatas 200 feet & kurang dari 30 feet \\
\hline Bandwidth & tinggi & rendah \\
\hline Issu keamanan & $\begin{array}{l}\text { dapat terjadi, masih dapat dikendali } \\
\text { kan. }\end{array}$ & sangat jarang \\
\hline Kecepatan & lebih banyak & kurang banyak \\
\hline Central Access Point & $\begin{array}{l}\text { Dengan menemukan router pusat } \\
\text { dari jaringan nirkaberl }\end{array}$ & $\begin{array}{l}\text { Dengan memeriksa panel } \\
\text { kontrol bluetooth }\end{array}$ \\
\hline
\end{tabular}

\subsubsection{HomeRF}

Tabel 2 : Perbandingan antara 802.11 b dan Bluetooth

Dirancang pada tahun 1998 oleh Kelompok Kerja Frekuensi Radio Rumah untuk pengguna rumahan untuk memungkinkan komunikasi nirkabel antara komputer dan perangkat nirkabel lainnya. HomeRF bekerja pada pita frekuensi $2.4 \mathrm{GHz}$ dengan kecepatan data sekitar 1 Mbps. Jangkauan komunikasi untuk HomeRF adalah sekitar 50 meter dan tujuan utamanya adalah untuk membangun jaringan yang dapat dioperasikan untuk keluarga.

Ada sesuatu yang sama antara teknologi HomeRF dan Bluetooth. Keduanya beroperasi pada pita frekuensi $2.4 \mathrm{GHz}$ dan semuanya dirancang untuk aplikasi jangka pendek, daya rendah. Ada juga perbedaan lainnya yaitu HomeRF dirancang untuk lingkungan jaringan rumah tetapi teknologi Bluetooth dioptimalkan untuk ponsel. Jangkauan komunikasi HomeRF sekitar 50 meter dan Bluetooth sekitar 10 meter. Kedua teknologi ini memiliki kecepatan yang sama sekitar $1 \mathrm{MBps}$ tetapi HomeRF versi 2.0 memiliki kecepatan data hingga $10 \mathrm{MBps}$, sehingga HomeRF membutuhkan daya lebih dari Bluetooth. (Brent : 2011).

\section{METODE PENELITIAN}

Metode yang dilakukan dalam melakukan penelitian ini adalah dengan mengumpulkan data terkait dengan penelitian yang akan dilakukan berupa :

\subsection{Lokasi Pengumpulan Data}

Gedung STMIK Kharisma Karawang yang terdiri dari 3 Lantai dimana pada Lantai 1 terdapat 4 ruang kelas, 1 labolatorium, kantin dan area public. Dilantai 2 terdapat ruang BAAK dan BAUM, 4 ruang lab, 1 ruang perpustakaan dan 2 ruang kelas, sedangkan dilantai 3 terdapat 2 ruang kelas dan 1 ruang AULA. Jumlah Access point (AP) disesuaikan dengan banyaknya ruang disetiap lantainya dan setiap ruang memiliki 1 AP.

\subsection{Mekanisme Kerja Penelitian}

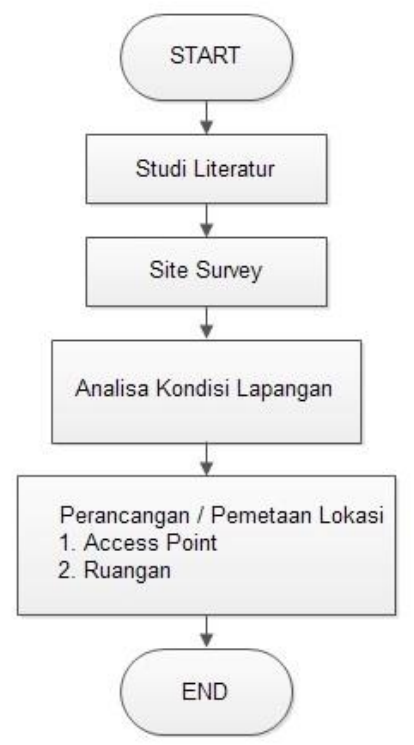

Gambar 3 : Flow Kerja 
Pembuatan alur atau proses penelitian dari tahap awal sampai selesai, sehingga memudahkan proses pengukuran system agar mudah untuk menganalisa. Tahap alur kerja penelitian ditunjukan pada gambar 3 .

\subsection{Data yang diperlukan}

- $\quad$ Posisi access point

- Type access point yang digunakan

3.4

- Pemetaan ruangan pada setiap lantai gedung kampus

Survey Site

- Berisikan rancangan/skema dari ruang kelas dan letak dari AP

- Mengukur luas masing-masing ruang kelas untuk setiap lantainya

- Berapa banyak AP untuk setiap lantainya

3.5

- Mengidentifikasi area dan physical bangunan

\section{Analisis Kebutuhan}

Dari hasil survey yang dilakukan bahwa seluruh AP terhubung ke ruang server yang berada di lantai 2, dimana untuk lantai 3 tersedia 3 buah AP yang terpasang dimasing-masing ruang kelas, dilantai dua terpasang 6 buah AP yang terpasang di 5 ruang kelas dan 1 AP terpasang di area public dan dilantai 1 terpasang 5 buah AP dimana 4 buah terpasang diruang kelas dan 1 AP terpasang di area public.

Langkah berikutnya membuat design dari gedung kampus dengan cara melakukan wawancara kepada pihak terkait di STMIK Kharisma mulai dari lantai 1 sampai lantai 3 untuk mengetahui alokasi ruang dan jumlah dari ruangan yang ada. Alokasi access point yang terpasang disetiap lantai untuk mempermudah dalam menggunakan aplikasi Ekahau sebagai pendeteksi sinyal dari access point.

\subsection{Hasil Penelitian dan Pembahasan}

Dari hasil pengecekan yang dilakukan dengan menggunakan aplikasi Ekahau Site Survey, didapat hasil sebagai berikut:

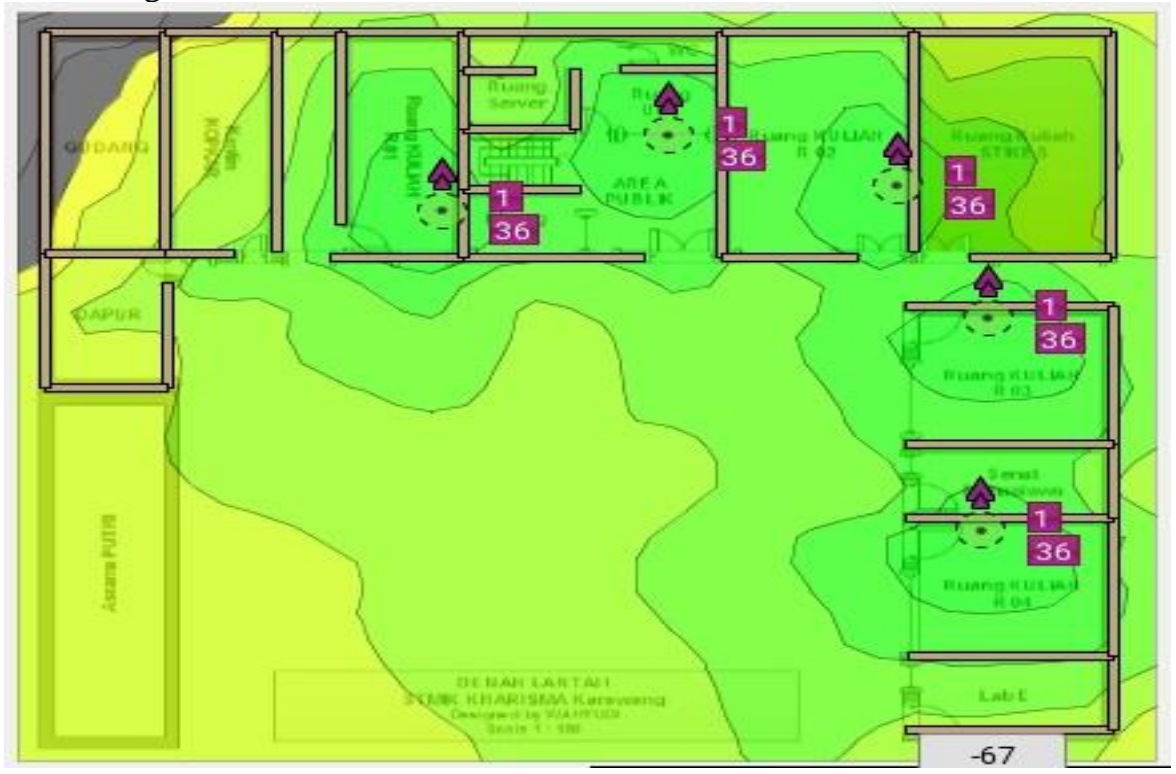

Gambar 3 : Denah Lantai 1

Pada denah lantai 1 terlihat bahwa terdapat 5 AP yang dengan tanda 1:36 dan warna disekitar AP tersebut berwarna hijau tua yang menandakan bahwa signal yang diterima disekitar lokasi tersebut sangat kuat sedangkan yang berwana kuning menunjukan signal yang diterima disekitar lokasi tersebut lemah dan abu-abu menunjukan tidak ada signal. 


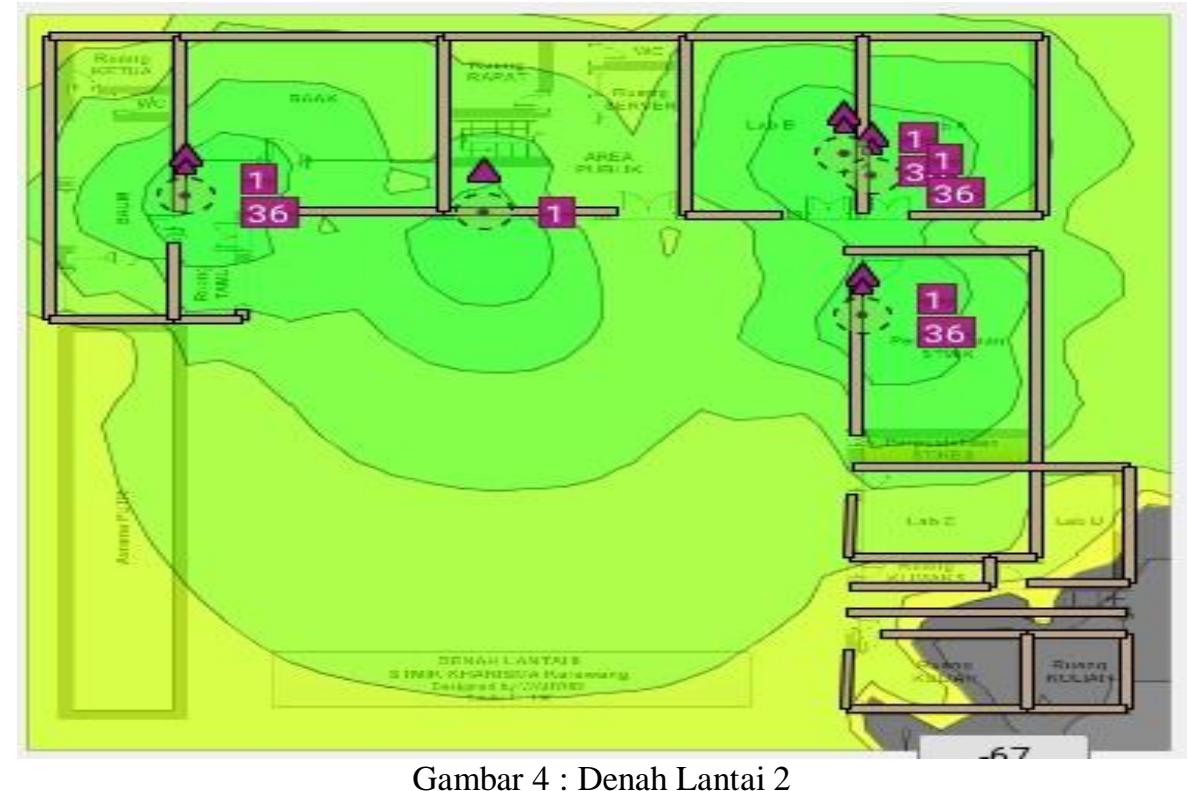

Pada denah lantai 2 terlihat bahwa terdapat 5 AP yang dengan tanda 1:36 dan warna disekitar AP tersebut berwarna hijau tua yang menandakan bahwa signal yang diterima disekitar lokasi tersebut sangat kuat sedangkan yang berwana kuning menunjukan signal yang diterima disekitar lokasi tersebut lemah dan abu-abu menunjukan tidak ada signal. Terlihat jelas bawah beberapa ruang kelas belum terjangkau oleh signal AP.

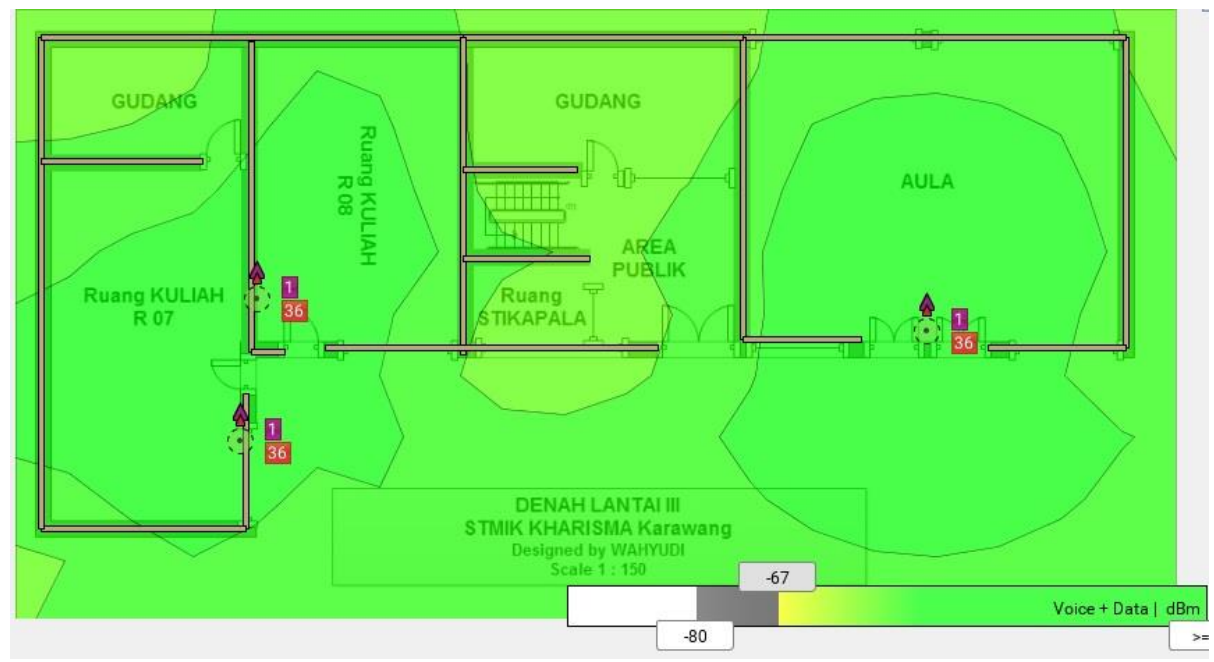

Gambar 5 : Denah Lantai 3

Pada denah lantai 3 terlihat bahwa terdapat 3 AP yang dengan tanda 1:36 dan warna disekitar AP tersebut berwarna hijau tua yang menandakan bahwa signal yang diterima disekitar lokasi tersebut sangat kuat dan seluruh ruangan maupun area public sudah terjangkau signal AP.

\subsection{KESIMPULAN DAN SARAN}

\section{KESIMPULAN}

Setelah dilakukan pengetesan dengan menggunakan aplikasi Ekahau site survey untuk setiap lantai gedung yang terdapat dikampus STMIK Kharisma maka dapat disimpulkan bahwa

1. Untuk lantai 1 khusus seluruh ruang belajar sudah terjangkau oleh signal AP dengan signal yang kuat kecuali ada beberapa public area, kantin dan asrama putri jangkauan signalnya kurang bagus hal tersebut dikarenakan hampir seluruh AP ditaruh di ruang kelas yang tertutup sehingga jangkauan dari AP jadi dibatas dikarenakan terhalang oleh tembok.

2. Untuk lantai 2 khusus seluruh ruang belajar sudah terjangkau oleh signal AP dengan signal yang kuat kecuali ada beberapa ruang kelas yang jaraknya cukup jauh dari AP sehingga tidak dapat terjangkau oleh AP khususnya ruang kelas yang berada diujung gedung. 
3. Untuk lantai 3 khusus seluruh ruang belajar sudah terjangkau oleh signal AP dengan signal yang kuat termasuk area public.

4. Terjadinya tumpang tindih jangkauan signal antara satu AP dengan AP lain

5. Jarak antara satu access point dengan access point lain ada yang tidak sama.

\section{SARAN}

1. Menambah access point khusus nya untuk area yang memiliki signal yang lemah khusus area yang berwarna kuning dan abu-abu

2. Jarak antar access point dengan access point yang lain sebaiknya memiliki jarak tertentu guna menghindari tumpeng tindih signal

3. Gunakan aplikasi ekahau heatmap guna mengetahui jangkauan dari masing-masing access point.

4. Menempatkan perangkat switch dimasing-masing lantai sehingga performance tetap terjaga dengan baik.

\section{DAFTAR PUSTAKA}

Bradley, M. 2019. Wireless Standards 802.11a, 802.11b/g/n, and 802.11ac. WWW document. Available at: https://www.lifewire.com/wireless-standards802-11a-802-11b-g-n-and-80211ac-816553[Accessed 02 April 2019].

Brent, A. 2001. HomeRF and Bluetooth Wireless Communication Compared. WWW Document. Available at: http://www.informit.com/articles/article.aspx?p=24265\&seqNum=4[Accessed 02 April 2017].

Difference Between. no date. Difference between Wireless LAN and Bluetooth. WWW Document. Available at:http://www.differencebetween.info/differencebetween-wireless-lan-andbluetooth [Accessed 12 March 2019].

Ekahau site survey 2012, Wi-Fi Planning, Verification, Troubleshooting User Guide. Available at : https://docplayer.net/52330285-Ekahau-site-survey-wi-fi-planning-verificationtroubleshooting-user-guide.html

Ji, Mengdi. May 2017., Designing and Planning a Campus Wireless Local Area Network. PDF Document. https://www.theseus.fi/bitstream/handle/10024/130087/Mengdi_Ji.pdf?sequence=1

Microsoft 2003, Aug 2009. How 802.11 Wireless Works. WWW Document. Available at: https://docs.microsoft.com/en-us/previous-versions/windows/it-pro/windows-server2003/cc757419(v=ws.10) [diakses 23 Maret 2019].

National Instruments. 2015. WLAN - 802.11 a, b, g and n. WWW Document. Available at : http://www.ni.com/tutorial/7131/en/[Accessed 08 March 2019].

Samraiz, T. 2014. Bluetooth. WWW Document. Available at: https://www.slideshare.net/Samraiz1/bluetooth-32312039 [diakses 02 Maret 2019].

Tada, Naren. June 2012. Trust Appraisal and Neighbour Defence Routing in Mobile Adhoc Network. WWW document. Available at https://www.researchgate.net/publication/319998320_Trust_appraisal_and_neighbour_defe nce_routing_in_mobile_adhoc_network [diakses 02 April 2019] 